\title{
Valdepeñas en la época de los Reyes Católicos: la ciudad
}

\author{
Ángela Madrid y Medina*
}

\section{ORIGENES}

Posiblemente el origen de nuestra población estuviera en una pequeña fortaleza, que coincidiría con la actual plaza mayor. Así lo entienden, entre otros, Corchado ${ }^{1}$ y Hervás ${ }^{2}$. De todas maneras la repoblación es más tardía que la de otros lugares próximos, como Manzanares, Daimiel ${ }^{3}$ o, en el Campo de Montiel, Alhambra, Torre de Juan Abad y, naturalmente, Montiel la cabecera ${ }^{4}$.

Valdepeñas, en cambio, está demasiado cerca de la frontera y entonces tampoco se encontraba en las principales vías de comunicación. Si existió, como dicen, esa torre, desapareció pronto, cediendo paso a la villa. Villa que tampoco estuvo amurallada como puede observarse en el plano, a diferencia de otras como Ciudad Real ${ }^{5}$ o Almagro ${ }^{6}$. Nuestro

* Profesora tutora. UNED.

' Corchado y Soriano, M., El Campo de Calatrava: Los Pueblos. Ciudad Real, I.E.M., 1982, pág. 480.

2 Hervás y Buendía, I., Diccionario Histórico geográfico de la provincia de Ciudad Real. Ciudad Real 1890, pág. 460.

${ }^{3}$ González, J., Repoblación de Castilla La Nueva. 2 vols. Madrid 1975 y 1976.

${ }^{4}$ Pueden verse mis artículos «Repoblación manchega bajomedieval: La Carta Puebla de Villamanrique", Cuadernos de Estudios Manchegos, núm. 16 (1985), págs. 131-150 y "Alfonso X el Sabio y La Mancha santiaguista», Espacio, tiempo y forma, serie III, núm. 2, UNED, 1989, págs. 205-218

${ }_{5}^{5}$ Villegas Díaz, L. R., Ciudad Real en la Edad Media. Ciudad Real, Diputación Provincial, 1981.

${ }^{6}$ Maldonado y Cocat, R. J., Almagro, Ciudad Real, I.E.M., 1989. 
pueblo, que, como veremos, experimenta un rápido e ininterrumpido crecimiento a partir del siglo XIV, tiene desde el principio una marcada vocación ciudadana, al igual que Villanueva de los Infantes ${ }^{7}$ con respecto al Campo de Montiel, cuyos núcleos de población se nos muestran mucho más ruralizados y con una traza menos centralizada, aunque jerarquizada y formando un conjunto armónico, y más irregular. Valdepeñas no fue nunca un pueblo replegado dentro de sus murallas.

\section{ESTRUCTURA URBANA}

A partir de documentación del Archivo Histórico Nacional y del Archivo de la Real Chancillería de Granada, podemos aproximarnos a su estructura y situación a fines de siglo $\mathrm{xV}$ y primera mitad del siglo XVI. El centro del casco urbano lo constituía, naturalmente, su plaza mayor, algo desplazada entonces al S.O. El trazado de las calles sigue una espina paralela a la Veguilla y el resto regular, casi en modalidad de tablero de damas, con dos líneas perpendiculares: el camino real (actualmente la calle Sebastián Bermejo) que cruzaba N-S, y la carretera de Levante (hoy Raimundo Caro-Patón, antes Torrecillas). Paralelo a ésta, al sur, queda el arroyo de la Veguilla, que tantos estragos ha venido causando, y que entonces se encontraba fuera de la población, si consideramos los datos sobre las huertas de sus márgenes. Referencias a los diezmos de huertos y huertas las vemos en los libros de visitas de la Orden de Calatrava. Por ejemplo, en la del 11 de enero de $1502^{8}$ y en la de $1509^{9}$. Don Eusebio Vasco hace una alusión más, que, aunque tardía para nuestros fines, no deja de tener interés:

«Ellos jugaban públicamente a los naipes (dice refiriéndose a unos trinitarios disidentes), iban de caza con escopeta y montera, acompañaban mujeres por las calles, las festejaban por las huertas de la Veguilla,

\footnotetext{
7 Me ocupé de ella por primera vez en "Villanueva de los Infantes y su Arte", Cuadernos de Estudios Manchegos, núm. 5, 1974, págs. 9-74.

a Archivo Histórico Nacional (AHN). Órdenes Militares. Consejo. Legajo 6110, núm. 7.

9 lbidem, núm. 55.
} 
todo con el fin de que llegase a oidos del Nuncio y del Rey y acabase la Reforma» ${ }^{10}$

$y$, por lo que a este aprendiz de arroyo se refiere, en la visita de 1502 , entre los bienes de la Encomienda, aparecen dos hazas ${ }^{11}$. La agricultura de regadío, por lo demás, se completaría en dicho año con el «diezmo de los alcazares (alcachofas) que se comen en verano", el pastel el cáñamo y el lino ${ }^{12}$.

\subsection{Viñas}

Lo mismo que sucede con la Veguilla puede decirse con respecto a otros lugares, hoy plenamente incorporados al tejido urbano. En el camino de los Llanos abunda el viñedo. Por ejemplo, en la descripción de 1495 de los bienes de la cofradía de Santiago se cita una viña en dicho lugar, aunque no especifica la extensión ${ }^{13}$. Sí, en cambio, concretan las 400 vides de la cofradía y hospital de san Bartolomé ${ }^{14}$. Otra viña se menciona en la visita de $1509^{15}$. Y en la relación de las capellanías de 1537 de la iglesia parroquial hallamos, entre las propiedades dejadas por Teresa García, «mujer que fue» de Pedro Vasco, para que se diga una misa por su alma a la semana, tres viñas en este camino: una de 1.300, otra de 1.000 y la tercera de 2.000 vides (aparte de otras tierras, alguna de ellas en "La Aguzadera") ${ }^{16}$. De las viñas dejadas por Francisco Verdejo, la más extensa (1.000 vides) está allí. Siendo de menor tamaño las del camino de Almagro, Aberturas, Daimiel... ${ }^{17}$. La viuda de Pedro Arroyo, Leonor Martínez, deja otras 600 vides ${ }^{18}$.

\footnotetext{
pág. 107.

1 AHN. Órdenes Militares. Visita de 1502, folios 1-15.

${ }^{12}$ Ibidem da).

${ }^{13}$ Apéndice documental. (Mi agradecimiento al Dr. Blas Casado Quintanilla por su ayu-

${ }_{14}$ Ibidem.

${ }^{15}$ Folios 9 al 11 de la misma.

${ }^{16}$ AHN. Órdenes Militares. Consejo. Legajo 6079, núm. 50, folios 182-184.

17 Ibidem, folios 186-187.

${ }^{18}$ Ibidem, folios 192-193.
}

10 VASCO Gallego, E., Valdepeñas cuna de la Descalcez Trinitaria. Valdepeñas 1912, 
Hemos de señalar que, si bien la extensión del viñedo en este siglo aún no era grande, alrededor del $20 \%$ de la superficie cultivada ${ }^{19}$, en esta centuria y la anterior, Valdepeñas, junto con Almodóvar, ya destaca en el Campo de Calatrava por este cultivo.

\subsection{Ermita de san Marcos}

Tampoco llegaba la población a san Marcos. La visita del 1537 nos habla de la cofradía y ermita de san Marcos, «ques junto a esta villa», la cual necesita reparos ${ }^{20}$. Lo mismo que la ermita, también con cofradía, de santa María Magdalena, de la que igualmente se afirma «que es junto a esta villa" y que es otra que necesita ser reparada. $Y$ hacer obras nuevas, como acabar de cubrir la casa de la santera ${ }^{21}$. La ermita de la Virgen de la Cabeza, sostenida por pastores, todavía en el siglo XVIII, como ocurría con la propia de san Marcos, se encontraba fuera del casco urbano 22 .

\subsection{Barrios}

Una villa, pues, de proporciones bastante más reducidas que la actual ciudad, como es lógico, pero que en 1583 se consideraba «grande de casi dos myll vezinos y de casas y calles muy anchas y muy extendidas» ${ }^{23}$. El número de vecinos que, como se sabe, son los cabeza de familia, es una cifra nada despreciable para la época. Pensemos que Almagro, cabecera del Campo de Calatrava, con 1.000 vecinos en 1520 estaba por debajo ${ }^{24}$, que Villanueva de los Infantes, cabecera del Campo de Montiel, en 1575 no pasaba de 1.300 vecinos $^{25}$ y que Tomelloso,

19 Solano Ruiz, E., La Orden de Calatrava en el siglo Xv. Sevilla, Universidad, 1978. LOPEZ-SALAZAR PÉREZ, J., Estructuras agrarias y sociedad rural en La Mancha (siglos XVIXVII). Ciudad Real, I.E.M., 1986.

20 lbidem, fols. 115-119.

21 Ibidem, fols. 149-152.

22 Era sostenida por pastores.

23 Archivo de la Real Chancillería de Granada (ARCHG), sala 508, legajo 2083, plaza núm. 7.

${ }^{24}$ Solano Ruiz, E., op. cit., pág. 195.

${ }_{25}$ VIÑAS, C. y PAZ, R., Relaciones de los pueblos de España ordenadas por Felipe II. Ciudad Real. Madrid, CSIC, 1971, pág. 590. 
pongamos por caso, en 1544 estaba naciendo, con un total de 31 vecinos de los que, gracias, una vez más, al archivo granadino, conocemos nombre y apellido ${ }^{26}$.

Referencias tardías nos hablan de algún barrio: el de san Nicasio, por ejemplo. $Y$, en la actualidad alguna de estas "calles extendidas" conserva el nombre de un gremio, como la calle Bataneros, que ya entonces debía de existir. En cualquier caso la actividad artesanal no parece que escasease. Alguna relacionada con la construcción, cosa lógica en un pueblo que se está expansionando. En la visita de 1502 hay diezmos sobre ladrillo, teja y cal, carga de barro y sobre algún otro que no menciona Emma Solano en su imprescindible obra de la Orden de Calatrava, como los tejadores y las "fandillas de palo», que acaso tienen relación con las cubiertas de madera utilizadas, sobre todo, en las construcciones mudéjares. Tampoco cita Solano el diezmo de "cántaros y ollería» ${ }^{27}$.

\subsection{Casas}

Las casas de esas calles debían de adaptarse al esquema general de la zona en cuanto a estructura y materiales, muchos de los cuales ya quedan reflejados. Luego hablaremos de la casa de la encomienda. Para las de los vecinos podemos recurrir a la descripción, por ejemplo, de las de El Viso, utilizando información de sus Relaciones Topográficas, hasta ahora inéditas y publicadas recientemente. Dice el texto:

«los edificios de las casas... son de tapias de tierra ordinariamente, haziéndoles su çimiento de piedra e barro; y unos los alçan de tres y de quatro tapias en alto y otros a mas, y cada uno como puede; y se cubren de teja; y la madera la traen... y vigas..., cada uno según su poder y voluntad $" 28$.

Tenemos noticias de algunas casas particulares: Teresa García, junto a las tierras ya señaladas, deja a la iglesia una casa entre las de

26 ARCHG. Cabina 511, legajo 2272, núm. 10.

${ }^{27}$ Lo encontramos en la ya mencionada visita del 11 de enero de 1502.

28 Villalobos Racionero, l., «Relaciones de los pueblos de España ordenadas por Felipe II. Villamayor del Campo de Calatrava. El Viso del Puerto del Muladar». Cuadernos de Estudios Manchegos, núm. 19 (1990), pág. 340. 
Hernán Gallego y Juan García Silvestre ${ }^{29}$. Francisco Verdejo, otra situada entre las de Juan Ybáñez y Antón Palomares ${ }^{30}$. La beata Elvira Martine de Recatia se limita a donar unas llaves, aparte de una tinaja y un majuelo ${ }^{31}$. Las casas donde vivía. Las entrega Carolina Martínez de Arroyo, viuda de Juan Martínez ${ }^{32}$.

Inés Hernández de los Hijos, además de tierras y tres tinajas, deja unas casas entre las de Juan Martín y Andrés Flores el Viejo ${ }^{33}$.

\subsection{Edificios públicos}

Un seguimiento de edificios públicos nos permiten las visitas de 1502 y 1509. Por el horno de san Juan el concejo pagaba al año en la primera de estas fechas mil maravedís ${ }^{34}$. También cotizan la carnicería y la tienda - que tampoco incluye Solano en su estudio-. No sorprende, habida cuenta de las favorables condiciones viarias y de los medios del lugar, que hubiera una actividad mercantil intensa. De hecho el valor de las alcabalas en 1501 en Valdepeñas, con sus 343.586 maravedis ${ }^{35}$, era muy superior al de la mayoría de estas villas.

Retomando nuestra inevitable visita de 1502 encontramos otra noticia inédita: la obligatoriedad de shacer plaza de toda la caça que acoge dicha Orden». La caza era importante. Con una riqueza ecológica muy superior a la actual. Lo abalan los diezmos sobre los venados, el puerco montés, los hurones -estos últimos sólo existentes en Valdepeñas- y los «losados» o cotos.

No nos cabe duda de que existió un mercado semanal. Entre los derechos de la encomienda se encontraba el de "las trece cosas» ${ }^{36}$, que en la visita de Almodóvar se describen como aceite, queso, sal, sogas, ajos, higos, garbanzos, vinagre, papel, jabón, especias, cominos y greda ${ }^{37}$ y que sólo podían venderse un día a la semana.

\footnotetext{
${ }^{29}$ AHN. Órdenes Militares. Consejo 6079, núm. 50, fols. 182-184.

30 Ibidem, fols. 186-187 $\mathrm{V}^{\circ}$

${ }^{31}$ Ibidem, fols. 196-197.

${ }^{32}$ Ibidem, fols. 200-201 v.

33 Ibidem, fols. 202-203.

34 Vid. Visita correspondiente.

35 Solano Ruiz, E., op. cit., pág. 357.

${ }^{36}$ Ibidem, pág. 340 .

${ }^{37}$ Ibidem, pág. 181.
} 
Había tiendas en la plaza. Martín López y su mujer Elvira López donan a su capellanía una tienda en la plaza, junto a las de Simón Rodríguez y Diego Sánchez de Villarreal ${ }^{38}$. Pero no estaban en la plaza todas las tiendas, como ocurría habitualmente. Los visitadores se quejan en 1493 de que la dispersión de las tiendas impide que se guarde «la onestidad y onrra de las mujeres" ${ }^{39}$. A pesar de lo cual noventa años después el problema aún no se había resuelto. En 1583 nueve moriscos pleitean con el concejo porque quieren mantener las tiendas en sus casas. Alegan que no puede prohibírseles por las características de calles y casas (se refieren a la amplitud), que ello no va contra las leyes y costumbres y que en todo el reino existe libertad de situar las tiendas de los vecinos en cualquier lugar del pueblo. Es más, en todos los lugares las tiendas están repartidas. Que les causa grave trastorno tener las tiendas donde las tienen desde que los alcaldes, regidores y gente rica de la villa han puesto en la plaza las suyas y lo que intentan es elevar los alquileres y tener ocupadas esas tiendas. No puede deberse, en su opinión, a evitar fraudes, porque los alcabaleros ya se encargan de cobrar. En cambio, teniéndolas en sus casas (y al ser pobres carecen de medios para sostener dos locales y las tiendas de la plaza son pequeñas para vivir) evitan desplazamientos y hay una mayor flexibilidad en el horario al público.

Estos argumentcs no parecen convencer al concejo, insistiendo en que el desplazamiento no es un trastorno, puesto que hay que ir a la plaza a la carnicería y pescadería y que el control es mayor evitando "el hurto y otros malefiçios de los esclavos» ${ }^{40}$.

\subsection{Casa de la encomienda}

También en la plaza, que no contaba con los soportales adosados después, se encontraba la casa de la encomienda. Los visitadores de 1509 , tras comprobar que se habían llevado a cabo los encargos hechos en anterior visita, ven

\footnotetext{
38 Visita de 1537, fols. 198-199.

39 Solano RuIz, E., op. cit., pág. 352.

40 Transcribo esta documentación, procedente del ARCHG, en Documentos sobre el municipio valdepeñero a fines del siglo XVI. Valdepeñas, colección «Juan Alcaide», 1983.
} 
«el aposento alto el qual a menester solarse la sala y cámara que sale sobre la calle y el retrete y enluzir por de dentro y por de fuera la puerta que se abryó en el dicho retrete y revocar las paredes del dicho aposento que están caydas en çiertas partes e asy mismo repararse lo del corredor que está sobre el patio en las partes que lo ovyera menester, por tanto vos mandamos que lo hagays hazer todo muy bien fecho y reparado:

Otrosy vimos el palacio que está en saliendo de la cosyna a la mano yzquierda en el qual está una vyga quebrada e asy mismo vymos el horno el qual está descubierto por tanto vos mandamos que hagays poner la dicha vyga en el dicho palaçio e hagays hazer una casa bien fecha sobre el dicho horno para que puedan cozer el pan syn estar al sol e al agua e asy mismo hagáis poner una puerta en la caballeriza de la dicha casa las quales dichas obras de parte de su alteza y horden vos mandamos...

$E$ porque hallamos que la aposento nuevo tenía trigo vos mandamos que de aquí adelante en el dicho aposento no se eche pan ninguno porque el aposento se estraga e asy mesmo fallamos que en la bodega de la casa el dicho mayordomo tenya paja por tanto vos mandamos que de aquí adelante en la bodega no aya pajar salvo en la casilla que es tajando a la caballeryza a la mano yzquyerda que está cobyerta" ${ }^{41}$.

\subsection{Iglesia mayor}

La iglesia mayor de Nuestra Señora santa María, actualmente de Nuestra Señora de la Asunción, durante el reinado de los Reyes Católicos aún se estaba construyendo, con toda seguridad. En una provisión de 1567 se explica que:

«está por acabar de haçer una capilla qesta encima de la puerta de la unbría e ansí mismo falta por haçer del todo otra capilla en la parte de hacia la plaça para que la dicha yglesia esté en cruz questo es muy nezesario que se haga por la mucha gente que hay en la dicha villa... E ansí mismo que se acabe de armar el texado... se acabe la sacristía... y la torre..." ${ }^{42}$.

La visita de 1537 nos hace una relación de orfebrería, ornamentos, ropas y atavios de la imagen de la Virgen ${ }^{43}$. Posee la iglesia tres casas, doce viñas y otras tierras (en visitas anteriores se menciona el «pie de

${ }^{41}$ AHN. Órdenes Militares, Consejo. Legajo 6110, núm. 55, fols. 9-11.

${ }^{42}$ AHN, Órdenes Militares. Toledo. Legajo 44378 , fols. 70 y 70 v. $^{\circ}$

${ }^{43}$ Folio 229. 
altar»), además de los bienes «que mandó» Pedro Muñoz del Olmo. Les pareció que la pila bautismal se encontraba en buen estado, pero en la sacristía había que hacer unos cajones. El órgano se había quitado de su tribunilla con motivo de las obras. Dicen que se vuelva a poner en su sitio. Les preocupa que «En la puerta de la mano derecha como entran por la plaça está un salmer quebrado" ${ }^{44}$ y que puede matar a alguien que pase debajo. Les satisfizo la capilla que se había hecho por la parte de la sacristía y elogian el retablo en construcción. Piden que agilicen las obras «pues en ello hazeys servicio a Dios Nuestro Señor e honrrays vuestro pueblo» ${ }^{45}$.

\subsection{Religiosidad popular}

11. No vamos a insistir en las ermitas, cofradías y hospitales, estudiados por M. ${ }^{\text {a }}$ Raquel Torres en el período comprendido entre $1491 \mathrm{y}$ $1510^{46}$. En el apéndice incorporamos, a modo de ejemplo, una descripción de 1495 de las cofradías de Santiago, san Sebastián y san Bartolomé, las dos últimas con hospitales, aunque su dotación era más bien modesta.

En la visita de 1537 no se mantiene, sin embargo, la situación indicada hasta 1510. Han desaparecido la cofradía de santa María de Gracia, la ermita, cofradía y hospital de san Sebastián y la cofradía y ermita de san Nicasio. Permanecen la cofradía de santa María de Agosto, la cofradía (aunque no la ermita, ni el hospital que cita Raquel Torres) de Santiago llamado ahora «el Viejo». La cofradía y hospital de san Bartolomé. La cofradía, pero no el hospital, de san Juan. Aparecen, en cambio, la cofradía y hospital de Nuestra Señora de la Asunción, la cofradía y ermita de san Marcos, ya citada, la ermita de Nuestra Señora de Aberturas, la cofradía y el cabildo del Corpus Cristi, el voto y cofradía de san Lorenzo, la cofradía de san Agustín, la cofradía y cabildo de san Andrés y la mencionada antes ermita y cofradía de santa María de Magdalena ${ }^{47}$.

44 De la misma visita, folio $239 \mathrm{v}$.

45 Ibidem, folio 240. Puede verse en «Aportaciones documentales a la Iglesia de Nuestra Señora de la Asunción de Valdepeñas", Cuadernos de Estudios Manchegos, núm. 20 (1990), págs. 357-369.

46 Torres Jiménez, M. ${ }^{a}$ Raquel., Religiosidad popular en el Campo de Calatrava. Ciudad Real, I.E.M., 1989.

47 Folios 111-160 de dicha visita. 


\section{SOCIEDAD}

Vamos a referir también aspectos como el de los oficios concejiles. En otra ocasión publicamos un pleito de 1569 con motivo de la elección de funcionarios ${ }^{48}$. Señalaremos al respecto únicamente que todavía en 1583 el concejo era abierto, convocándose al vecindario a «son de campana teñida", aunque observamos elementos propios del Regimiento. Tampoco nos detendremos en el aspecto jurídico, limitándonos a indicar que en la visita de 1502 aparece un derecho de "penas y limosnas" y otro de "tablero", es decir, multas sobre el juego de azar ${ }^{49}$.

Pero el pleito de 1569 nos aproxima a la estructura social de nuestra población: De los seis electores nombrados sobre el padrón de vecinos, uno es hidalgo, otro mercader y los cuatro restantes labradores. En realidad del período que da título a esta modesta aportación, sólo hemos localizado también a un hidalgo, Diego de Merlo, asistente de Sevilla, que con el marqués de Cádiz decide tomar al asalto el 28 de febrero de 1482 la ciudad de Alhama, en el corazón del reino de Granada.

Tampoco podemos profundizar mucho en minorías étnicas. Sólo el impuesto del «oro y el moro» de las visitas de principios del siglo XVI nos haría pensar en la posibilidad de población mudéjar, que, algo después, como ya hemos visto, existió sin duda. En conclusión, mayoría de labradores, con un ingrediente de mercaderes y mudéjares y un número indeterminado de hidalgos en un pueblo en pleno desarrollo con riqueza ecológica que hoy añoramos, que se "honra» en construir un templo que se convertirá en monumento nacional, y en el que la vid ya empieza a destacar hasta alcanzar el puesto que hoy ocupa.

${ }^{48}$ Documentos sobre el municipio... op. cit., págs. 28-89.

49 Visita antes mencionada. 


\section{APÉNDICE DOCUMENTAL}

1.495, mayo, 21-23

Inventario de los bienes de las cofradías de Santiago, San Sebastian y San Bartolomé de Valdepeñas, realizado por frey Juan de Almagro, sacristán del convento de Calatrava, y frey Pedro de Aguayo, comendador de Moratalaz, visitadores de Calatrava.

Consejo. Visitas, legajo 6.109.

Archivo Histórico Nacional (AHN). Órdenes Militares.

Inventario de las heredades e bienes que tiene la cofradía del Señor Santiago.

Viñas:

- una viña camino del cominar

- otra viña en la cañada romero

- otra viña camino de los llanos

- otra viña camino de Daymiel y todas éstas están en el libro del cabildo

Tynajas:

- tyene así mismo çinco tynajas buenas ricas e grandes

Tierra:

- tyene una tierra de pan llevar que puede cabar

- item dos pendones del cabildo

- un arca para tener la cera

Examinación de las cuentas de la cofradía del señor San Sevastián de la villa de Valdepeñas:

- un cáliz de plata con su patena

- un alva con su vestimenta de lienzo con su adiçión

- una manta obrada buena e un repostero que está en el altar

- un acetre bueno e dos candelabros 
- un arca de pino en que están estas cosas e un arqueta en que está el ara

- un par de ampollas

- un par de manteles de lino raydos

- un paño de lienzo con unas vandas que están con el ara

- una sávana de lino de tres piernas orillada con çintas de seda

- un ante cama de lino de cuatro piernas de colores

- dos destajos viejos que están en las gradas del altar

- otro par de manteles de lino de tres varas a media

- una campanilla pequeña e un campillo de lienzo

Ropa del ospital:

- una manta mal hilada de colores

- otras dos mantas mal hiladas traydas de tirillas

- otras mantas mal hiladas trayda blanca y pardilla

- un reçel mediado e otra manta mal hilada con listas prietas a los cabos

- otra manta trayda de tirilla

- otra manta blanca mal hilada trayda e otras dos mantas mal filadas con listas prietas a los cabos

- otra manta mal filada pardilla e blanca e otra manta blanca mal filada trayda.

- item seis almadraques razonables e seis sábanas buenas

- una caldera grande e una sartén de fierro buena e dos asadores

- item dos candiles e cinco medias camas de madera

- una cama sobre unos vancos

- una cuchara de fierro e un cubo para sacar agua e un xergo de lana

- dos vancos el uno de pino el otro de roble

- un par de manteles razonables

- un almohada de lienzo trayda

- tres maderos e un pedazo de ropia e seys cabeçales razonables

- dos cabeçeros e otro par de manteles de lino de tres varas

- una sávana de cubrir

- un cabeçal e una coçedra

- una sábana de cáñamo que dio la de Alonso Peréz de la Mata

Inventario de la ropa e bienes de la cofradía e ospital de Señor San Bartolomé de la villa de Valdepeñas. 
Ropa del ospital:

- un almadraque de xerga

- un cabezal de lienzo

- una manta mal hilada

- un reçel viejo

- una nosa parda

- una nosa vieja

- dos mantas mediadas

- otra manta blanca con un cabezal

- un almadraque pardo bueno

- diez y seis cabezales nuevos e viejos

- otras dos medias mantas

- una coçedra e dos sábanas medianas

- un arca de pino viejo

- quatro dobles de pino

- una tabla de mesa

- una sartén vieja

- un par de manteles

- un almadraque e una manta mal hilada

Viñas:

- quinientas vides que son camino del conimar

- una viña de quatrocientas vides camino de los llanos

- camino del Moral docientas e cinquenta vides

- camino de Almagro mill e novecientas vides

- dos tinajas de uva de quarenta arrovas

- dos pedazos de tierra en el rincón

- una faça camino de Daymiel en los llanos dos hazas otra haza camino del Peral 


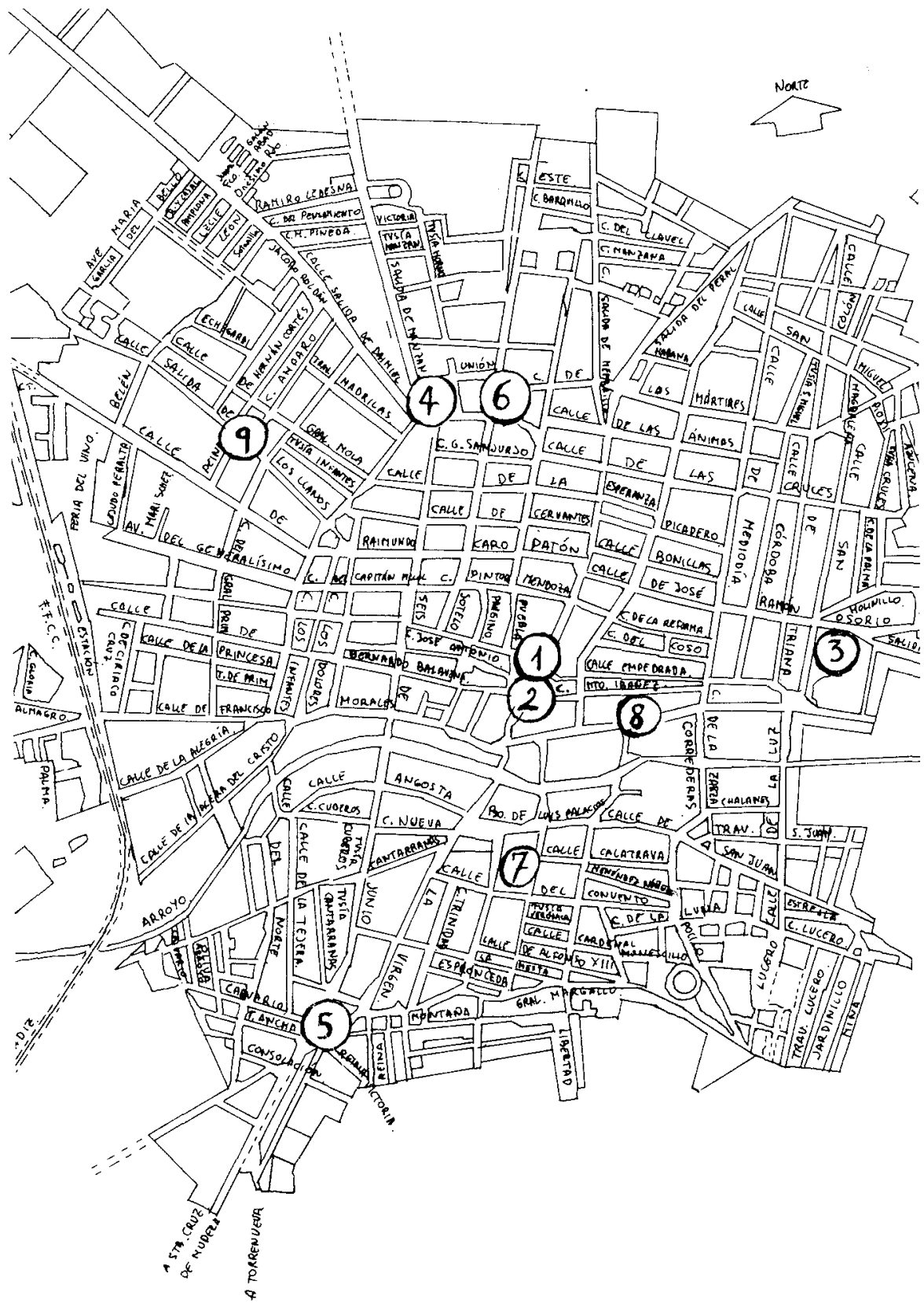

1. Iglesia de Santa María-2. Casa de la Encomienda.-3. San Nicasio.-4. San Marcos.-5. Virgen de la Cabeza.-6. ¿Santa María Magdalena? -7. San Sebastián.8. Calle Bataneros.-9. Salida de los Llanos. 